NASA/TM-1999-206579

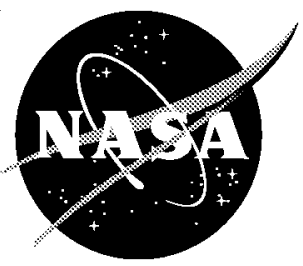

\title{
Design and Predictions for a High-Altitude (Low-Reynolds-Number) Aerodynamic Flight Experiment
}

Donald Greer and Phil Hamory

Dryden Flight Research Center

Edwards, California

Keith Krake

Sparta Inc.

Edwards, California

Mark Drela

Massachusetts Institute of Technology

Cambridge, Massachusetts 


\section{The NASA STI Program Office...in Profile}

Since its founding, NASA has been dedicated to the advancement of aeronautics and space science. The NASA Scientific and Technical Information (STI) Program Office plays a key part in helping NASA maintain this important role.

The NASA STI Program Office is operated by Langley Research Center, the lead center for NASA's scientific and technical information. The NASA STI Program Office provides access to the NASA STI Database, the largest collection of aeronautical and space science STI in the world. The Program Office is also NASA's institutional mechanism for disseminating the results of its research and development activities. These results are published by NASA in the NASA STI Report Series, which includes the following report types:

- TECHNICAL PUBLICATION. Reports of completed research or a major significant phase of research that present the results of NASA programs and include extensive data or theoretical analysis. Includes compilations of significant scientific and technical data and information deemed to be of continuing reference value. NASA's counterpart of peer-reviewed formal professional papers but has less stringent limitations on manuscript length and extent of graphic presentations.

- TECHNICAL MEMORANDUM. Scientific and technical findings that are preliminary or of specialized interest, e.g., quick release reports, working papers, and bibliographies that contain minimal annotation. Does not contain extensive analysis.

- CONTRACTOR REPORT. Scientific and technical findings by NASA-sponsored contractors and grantees.
- CONFERENCE PUBLICATION.

Collected papers from scientific and technical conferences, symposia, seminars, or other meetings sponsored or cosponsored by NASA.

- SPECIAL PUBLICATION. Scientific, technical, or historical information from NASA programs, projects, and mission, often concerned with subjects having substantial public interest.

- TECHNICAL TRANSLATION. Englishlanguage translations of foreign scientific and technical material pertinent to NASA's mission.

Specialized services that complement the STI Program Office's diverse offerings include creating custom thesauri, building customized databases, organizing and publishing research results...even providing videos.

For more information about the NASA STI Program Office, see the following:

- Access the NASA STI Program Home Page at http://www.sti.nasa.gov

- E-mail your question via the Internet to help@sti.nasa.gov

- Fax your question to the NASA Access Help Desk at (301) 621-0134

- Telephone the NASA Access Help Desk at (301) 621-0390

- Write to:

NASA Access Help Desk

NASA Center for AeroSpace Information 7121 Standard Drive

Hanover, MD 21076-1320 


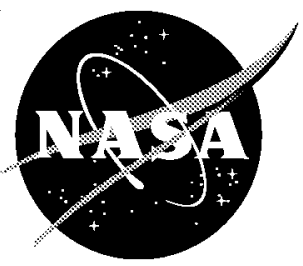

\section{Design and Predictions for a High-Altitude (Low-Reynolds-Number) Aerodynamic Flight Experiment}

Donald Greer and Phil Hamory

Dryden Flight Research Center

Edwards, California

Keith Krake

Sparta Inc.

Edwards, California

Mark Drela

Massachusetts Institute of Technology

Cambridge, Massachusetts

National Aeronautics and

Space Administration

Dryden Flight Research Center

Edwards, California 93523-0273

July 1999 


\section{NOTICE}

Use of trade names or names of manufacturers in this document does not constitute an official endorsement of such products or manufacturers, either expressed or implied, by the National Aeronautics and Space Administration.

Available from the following:

NASA Center for AeroSpace Information (CASI)

7121 Standard Drive

Hanover, MD 21076-1320

(301) 621-0390
National Technical Information Service (NTIS) 5285 Port Royal Road Springfield, VA 22161-2171 (703) $487-4650$ 


\title{
DESIGN AND PREDICTIONS FOR A HIGH-ALTITUDE (LOW- REYNOLDS-NUMBER) AERODYNAMIC FLIGHT EXPERIMENT
}

\author{
Donald Greer ${ }^{*}$ and Phil Hamory ${ }^{\dagger}$ \\ NASA Dryden Flight Research Center \\ Edwards, California \\ Keith Krake \\ Sparta Inc. \\ Edwards, California \\ Mark Drela ${ }^{\S}$ \\ Massachusetts Institute of Technology \\ Cambridge, Massachusetts
}

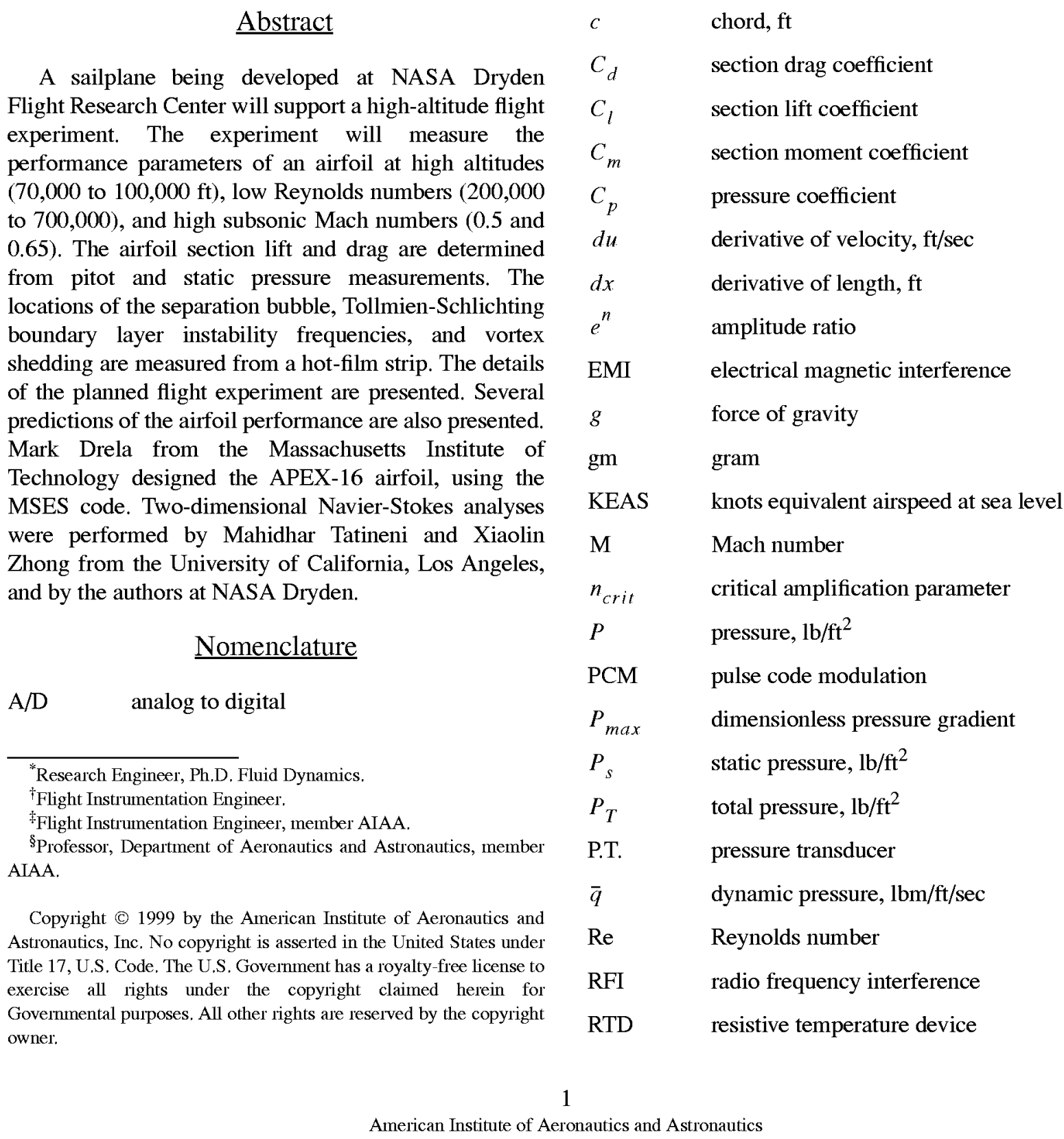

American Institute of Aeronautics and Astronautics 


$\begin{array}{ll}\text { sep } & \text { separation } \\ U_{x} & \text { uncertainty of the variable } x \\ x_{T R} & \text { transition location } \\ \alpha & \text { angle of attack, deg } \\ \gamma & \text { ratio of specific heats } \\ \theta & \text { momentum thickness } \\ v & \text { kinematic viscosity, ft/sec }{ }^{2} \\ & \text { Introduction } \mathbb{}\end{array}$

The need for cost-effective high-altitude vehicles to conduct atmospheric research has created interest in high-altitude (low-Reynolds-number) airfoils. In support of this need, NASA Dryden Flight Research Center is developing a sailplane called APEX that will measure the parameters affecting the performance of the airfoil in actual high-altitude flight. The APEX sailplane will be released from a high-altitude balloon from approximately $108,000 \mathrm{ft}$ altitude and then remotely piloted. Figure 1 shows a schematic of the flight mission.

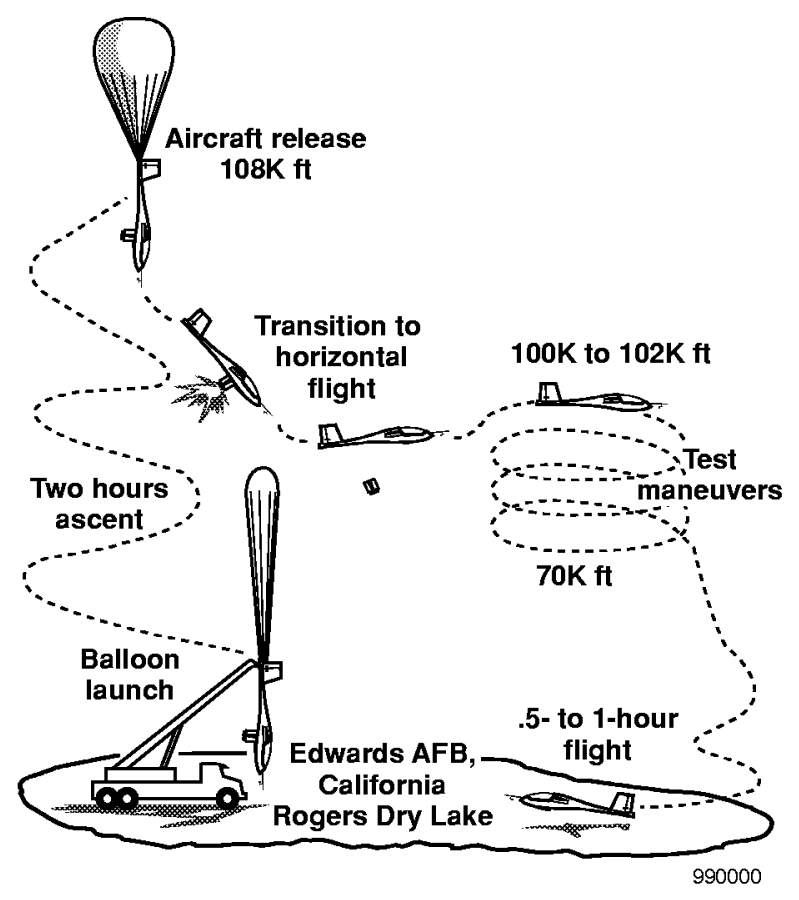

Figure 1. APEX mission profile.

\footnotetext{
"Use of trade names or names of manufacturers in this document does not constitute an official endorsement of such products or manufacturers, either expressed or implied, by the National Aeronautics and Space Administration.
}

The first $30 \mathrm{sec}$ after release from the balloon are the most critical for the APEX flight control system. Transition to horizontal flight occurs during this period with the assistance of four small rockets, which have a combined thrust of $784 \mathrm{lb}$. After the transition to horizontal flight, the airfoil parameters affecting performance are measured as the sailplane descends from 100,000 to $70,000 \mathrm{ft}$. The sailplane is then brought to a horizontal landing at the Rogers dry lakebed at Edwards Air Force Base, California.

Low-Reynolds-number airfoils typically exhibit laminar separation bubbles as shown schematically in figure 2. These separation bubbles are known to significantly affect the performance of an airfoil. The bubble is formed when the laminar flow separates as a result of encountering the adverse pressure region of the airfoil. The separated free shear layer is unstable, which amplifies the Tollmien-Schlichting instability waves. The free shear flow generally transitions rapidly from laminar flow to turbulent flow and then reattaches to the airfoil surface. The lambda shocks, which occur in the transonic flight regime, are expected to increase the amplification of the Tollmien-Schlichting instability waves.

The objectives of the APEX experiment are

- To increase the understanding of airfoil performance in the high-altitude, low-Reynoldsnumber, and high-subsonic-Mach-number flight regime.

- To obtain flight test data of airfoil performance parameters that can be used for validation of airfoil design codes.

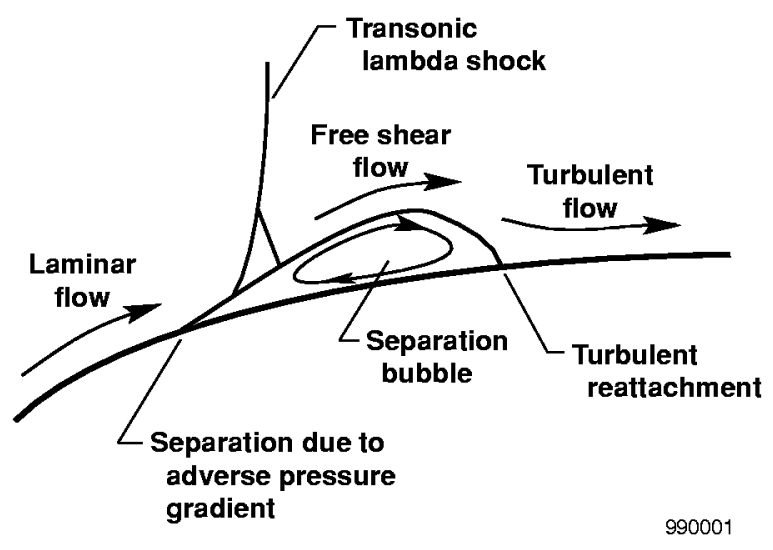

Figure 2. Laminar separation bubble. 
This paper presents a description of the APEX experiment. The design details used to determine the performance parameters of the airfoil will be discussed. A preliminary error analysis will also be presented. Various numerical models used to predict the airfoil performance parameters will also be discussed.

\section{Previous Research}

Several studies investigating the performance and characteristics of low-Reynolds-number airfoils have been performed. Mueller ${ }^{1}$ presents an excellent summary of the research before 1985. One interesting aspect that Mueller discusses is the hysteresis that often occurs in the drag polars. Mueller's wind-tunnel studies show that the airfoil performance, including the hysteresis, could be significantly affected by free-stream turbulence and surface roughness. LeBlanc et $\mathrm{al}^{2}$ performed wind-tunnel measurements on a Liebeck airfoil at low Reynolds numbers. The boundary layer velocity fluctuations in the separation bubble were measured with hot-wire anemometry. The measured velocity spectra of peak instability frequencies agreed with the predictions from linear stability theory analysis.

Howard and Kindelspire ${ }^{3}$ performed a wind-tunnel study of the free-stream-turbulence effects on an airfoil. Their investigation shows that transition develops more rapidly by increased free-stream turbulence and also that boundary layer instability growth is greatest when the turbulence length scale is on the same order as the boundary layer thickness. Dovgal et al. ${ }^{4}$ discuss several aspects of the instability associated with laminar separation bubbles including receptivity, linear instability, and nonlinear interactions.

Recent investigations of Pauley et al., ${ }^{5}$ Ripley and Pauley, ${ }^{6}$ and Muti Lin and Pauley ${ }^{7}$ show that the separation bubble may become unstable under certain conditions, and experiences periodic vortex shedding. Their transient incompressible Navier-Stokes analytical studies characterized the unsteady vortex shedding structure. Tatineni and Zhong ${ }^{8,9}$ performed a twodimensional, time-accurate Navier-Stokes analysis on the APEX-16 airfoil flow field. Their analysis indicates that the airfoil separation bubble is unstable and periodically sheds at the flight conditions of the APEX sailplane. A linear stability analysis also showed that the most dominant instability frequency matches the frequency of the periodic vortex shedding.

Drela $^{10}$ investigated high-altitude, low-Reynoldsnumber airfoils in the transonic flight regime with the
ISES code. An interesting aspect of this investigation is that airfoil performance in the high-altitude flight regime may depend largely upon the effectiveness of lambda shocks to increase the amplification of instability waves and increase the transition rate in the separation bubble. A conclusion is that experimental test data exploring laminar shock-boundary layer interactions and its effect on Tollmien-Schlichting instability waves would significantly reduce the uncertainties in the analysis.

Turbulence is expected to be a major factor in the performance of the APEX-16 airfoil. The length of the separation bubble depends on the growth of the instability waves within the free shear layer and transition to fully developed turbulence. The process by which free-stream turbulence enters the boundary layer and becomes amplified is known as receptivity. Qualitatively, the concept is simple: Free-stream turbulence of various amplitudes and wavelengths enters the boundary layer and either decays or grows. The most unstable wavelengths grow at the greatest rates and develop into Tollmien-Schlichting instability waves and eventually cause transition to turbulence. Generally, the larger the free-stream turbulence amplitudes, the quicker the boundary layer transitions to turbulence. Quantitatively, receptivity is a complicated subject that is not well understood. Reshotko ${ }^{11}$ summarizes the current understanding of receptivity. Although the receptivity process to transition is difficult to quantitatively predict, it is well known to be a strong function of free-stream turbulence as shown by Dryden et al. ${ }^{12,13}$ in several experiments measuring the critical Reynolds number of a sphere as a function of free-stream turbulent intensity. Fisher and Dougherty ${ }^{14}$ performed a series of transition measurements on a cone in wind tunnels and in flight. Their results show that the transition location is a function of the free-stream turbulence. The atmospheric turbulence in flight is very low and of large wavelength in relation to the thickness of the boundary layer.

Presently, no existing wind tunnel can provide the high-altitude $(70,000$ to $100,000 \mathrm{ft})$, low-Reynoldsnumber $(200,000$ to 700,000$)$, high-subsonic-Machnumber $(0.5$ to 0.65$)$, and low-free-stream-turbulentintensity ( 0.02 percent or less) environment necessary to accurately measure the APEX-16 airfoil performance. Natural atmospheric turbulence is the rationale for constructing the APEX research sailplane and measuring the in-flight airfoil performance parameters rather than performing a wind-tunnel study. 


\section{APEX Sailplane Description}

Murray et al. ${ }^{15}$ originally proposed the APEX sailplane as a modified Schweizer SGS 1-36 sailplane. As the APEX design proceeded, the sailplane evolved into the current configuration. Figure 3 shows the APEX sailplane geometry. The sailplane is $22.7 \mathrm{ft}$ long with a wingspan of $41.2 \mathrm{ft}$ and has a wing aspect ratio of 13.6. The experimental test section, where the performance parameters are measured, is at the midspan point of the right wing as shown in the figure. The sailplane is designed for a target gross weight of $600 \mathrm{lb}$ with a 5-g maneuver load factor. The airframe has been designed and is currently being fabricated by Advanced Soaring Concepts (Camarillo, California) from graphite/epoxy and boron/epoxy composites.

Drela designed the APEX-16 airfoil using the coupled viscous/inviscid MSES code. ${ }^{16,17}$ The coordinates and airfoil shape are shown in table 1 and figure 4, respectively. The airfoil dimensional tolerances for the wing construction are specified at \pm 0.005 in. to reduce the effects of surface roughness and waviness. The wing is a rectangular planform of the APEX-16 airfoil, as was shown in figure 3. The wing incorporates a 2-deg linear washin to reduce three-dimensional (spanwise) effects and to provide a more uniform section lift coefficient $\left(C_{l}\right)$ distribution over the experimental area of the wing.

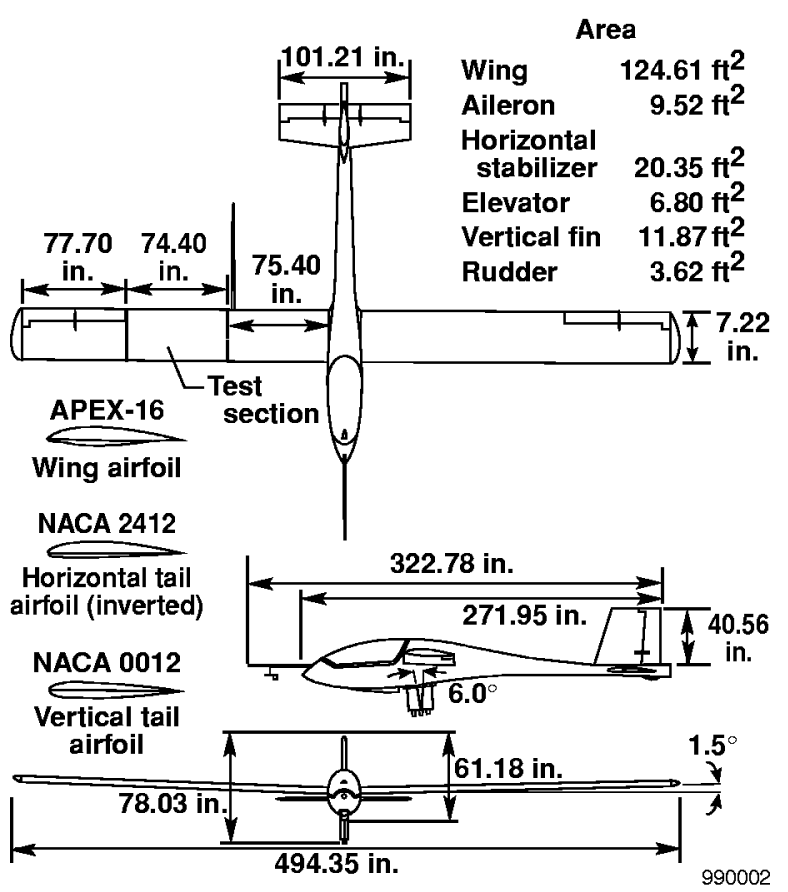

Figure 3. APEX three-dimensional view.
Table 1. Coordinates $(x, y)$, inches.

\begin{tabular}{|c|c|c|c|c|c|c|c|}
\hline \multicolumn{4}{|c|}{ Upper surface } & \multicolumn{4}{|c|}{ Lower surface } \\
\hline 0.00 & 0.00 & 16.23 & 3.29 & 0.00 & 0.00 & 16.96 & -1.41 \\
\hline 0.09 & 0.25 & 18.80 & 3.22 & 0.11 & -0.25 & 19.57 & -1.22 \\
\hline 0.51 & 0.64 & 21.35 & 3.05 & 0.56 & -0.43 & 22.20 & -0.99 \\
\hline 1.72 & 1.30 & 23.90 & 2.80 & 1.94 & -0.60 & 24.84 & -0.74 \\
\hline 3.81 & 2.00 & 26.44 & 2.45 & 4.47 & -0.81 & 27.48 & -0.49 \\
\hline 6.17 & 2.52 & 28.98 & 2.01 & 6.99 & -1.09 & 30.11 & -0.27 \\
\hline 8.63 & 2.89 & 31.50 & 1.50 & 9.45 & -1.43 & 32.70 & -0.08 \\
\hline 11.14 & 3.13 & 34.00 & 0.90 & 11.87 & -1.57 & 35.23 & -0.02 \\
\hline 13.69 & 3.26 & 37.22 & 0.00 & 14.38 & -1.54 & 37.22 & 0.00 \\
\hline
\end{tabular}

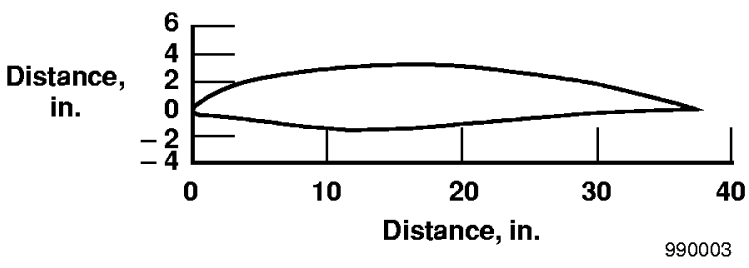

Figure 4. APEX-16 sectional (37.22-in. chord).

The forward undercut camber on the lower surface does not directly affect the separation bubble and was incorporated into the design to increase the maximum lift coefficient and decrease the pitching moment. The airfoil was designed to provide good performance throughout the entire APEX flight envelope. Figure 5 shows the predicted APEX flight envelope. The challenge of the design was to correctly predict the characteristics of the separation bubble without experimental data for code verification in the highsubsonic-Mach-number and low-Reynolds-number flight regime.

The experiment is limited by several design constraints. Weight is a major design consideration for the experiment. The gross vehicle flight weight for the sailplane is specified at $600 \mathrm{lb}$ to provide an adequate stall margin for attaining a ceiling altitude of $100,000 \mathrm{ft}$. The experiment is limited to 10 percent of the gross vehicle weight or $60 \mathrm{lb}$. Packaging the experiment is also another major design constraint. Much of the instrumentation electronics, including pressure transducers, accelerometers, and the hot-film anemometry, signal conditioning, and analog-to-digital (A/D) conversion cards, are in the wing next to the experiment. The electronic instrumentation is located 


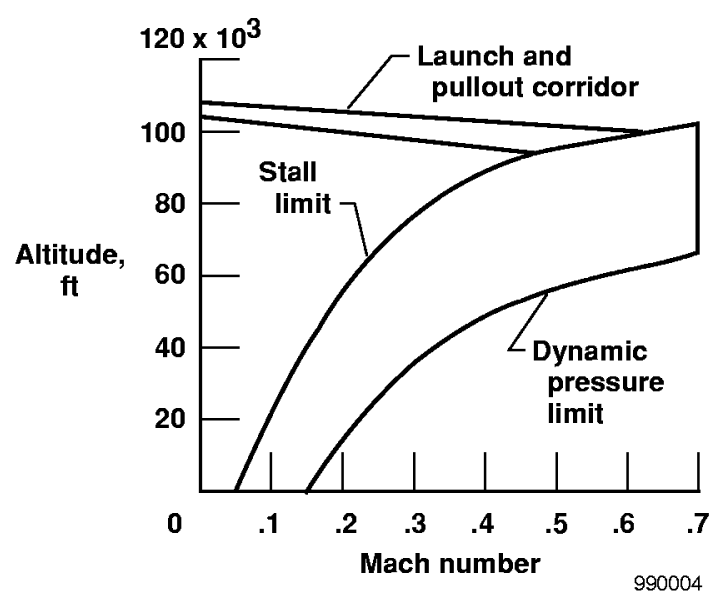

Figure 5. APEX flight envelope.

close to the experiment to minimize noise from radio frequency interference (RFI) and electrical magnetic interference (EMI). The wing chord is $37.22 \mathrm{in}$. with a maximum interior thickness of $5 \mathrm{in}$, which makes instrumentation packaging difficult. Another design constraint is the high altitude. The available off-theshelf instrumentation that can provide adequate range and accuracy at high altitude is limited. Some instrumentation had to be specifically designed for the experiment. The air density at $100,000 \mathrm{ft}$ altitude is approximately 1 percent of its value at sea level, which substantially lowers the convective cooling rates of the electronics to the air. Some electronics require a specialized cooling design to avoid overheating.

\section{$\underline{\text { APEX Experimental Description }}$}

The flight experiment to measure the performance parameters of the APEX-16 airfoil consists of three primary measurements:

- First, to measure section lift a series of static pressure taps circle the airfoil at one spanwise location.

- Second, to measure section drag a trailing rake sits behind the airfoil with a support sting.

- Third, to measure the separation bubble location, Tollmien-Schlichting frequencies, and vortex shedding a hot-film strip sits on the top surface of the airfoil.

Figure 6 presents a schematic layout of the airfoil instrumentation. In addition to the primary measurements, the instrumentation also includes a Kiel probe to measure free-stream total pressure, a trailing static probe to measure free-stream static pressure, a boundary layer rake to determine the velocity profile, a total temperature measurement, five integrating boundary layer rakes to determine the section drag developing over the upper surface, two integrating trailing rakes to determine total section drag, two vanes to measure angles of attack and sideslip, and three accelerometers to measure wing surface vibration.

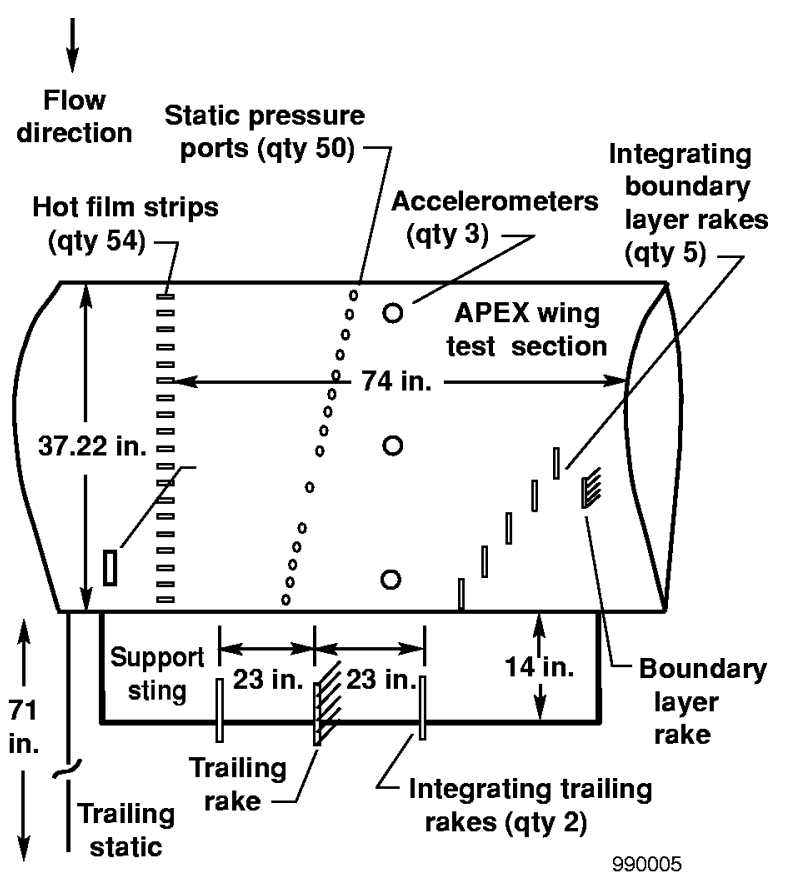

Figure 6. APEX instrumentation layout on right-wing test section.

\section{Pressure Measurement System}

Figure 7 presents a schematic of the pneumatic pressure measurement system. Fifty static pressure ports along the chord ( 30 on the upper surface and 20 on the lower surface) measure the pressure distribution over the airfoil. The ports have a 0.05 -in. diameter and are staggered at a 15-deg angle relative to the chord to prevent contamination from upstream ports. A trailing rake comprises 26 total pressure probes and 3 static probes to determine section $\operatorname{drag}\left(C_{d}\right)$. The rake is mounted 0.3 chord length aft of the airfoil where the static pressure is expected to be fully recovered.

The airfoil section drag is calculated from the rake pressures based upon the Jones ${ }^{18}$ method corrected for compressibility effects. A Kiel probe, located midchord, 8 in. from the lower surface of the airfoil, measures a reference total pressure $\left(P_{T}\right)$. A trailing 


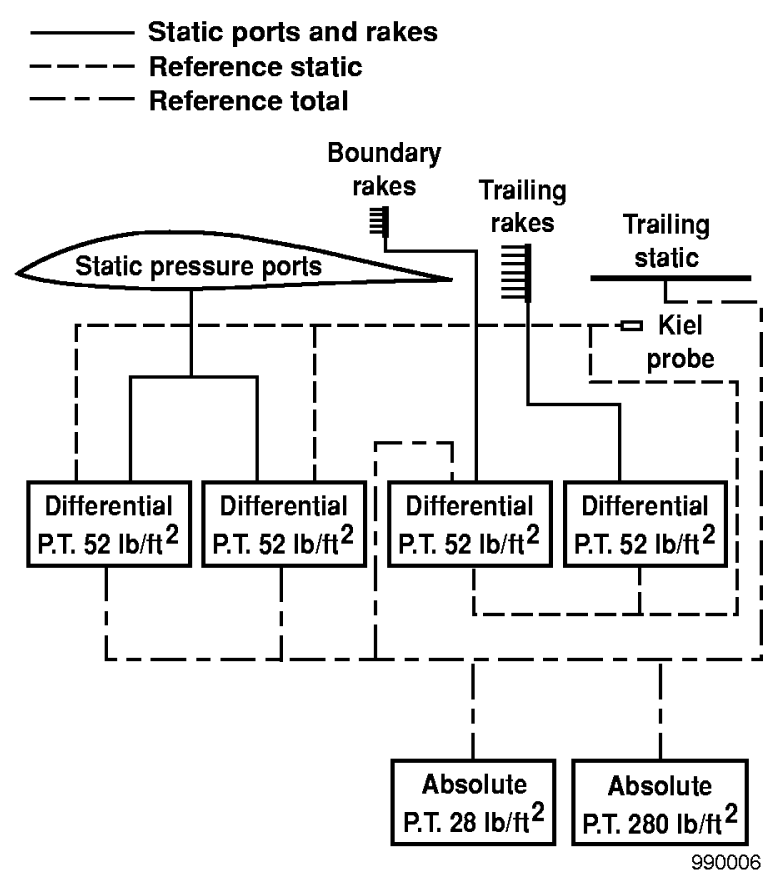

Figure 7. Pneumatic pressure measurement system for the right-wing test section.

static probe, placed three chord lengths aft of the airfoil, measures a reference static pressure $\left(P_{s}\right)$. A conventional boundary layer rake placed at 70-percent chord determines the boundary layer velocity profile development on the upper surface. Five integrating boundary layer rakes are located at 60-, 70-, 80-, 90-, and 100-percent chord, and two integrating trailing rakes are located at 0.3 chord lengths aft of the airfoil. The integrating rakes are multi-pitot probe rakes such as developed by Silverstein and Katzoff ${ }^{19}$ in which the pitot probes are plumbed into a common reservoir for a single average total pressure measurement. The average total pressure measurement has been shown by Drela" to be a direct determination of the sum of momentum thickness and displacement thickness from which drag can be calculated.

The pressure measurement system design uses four electronically scanned differential pressure transducers manufactured by Pressure Systems Incorporated (Hampton, Virginia) to measure differential pressure. The transducers are silicon peizoresistive pressure sensors with a range of $\pm 52 \mathrm{lb} / \mathrm{ft}^{2}$. This transducer was

\footnotetext{
"Drela, Mark, "Integrating Rake Design," private communication, 1995.
}

chosen because it is flight proven, lightweight $(3.7 \mathrm{oz})$, and small ( 1 by 4 by $1 / 2$ in.). Each transducer has 32 input pressure port channels. The input pressure is differentially measured against a reference pressure. The transducer may have only one reference pressure, either the static pressure from the trailing static probe or the total pressure from the Kiel probe as was shown in figure 7 .

The absolute pressure is measured by two Baratrons transducers manufactured by MKS Instruments Incorporated (Andover, Massachusetts). The transducers measure the static pressure in two ranges, 0 to $28 \mathrm{lb} / \mathrm{ft}^{2}$ and 0 to $280 \mathrm{lb} / \mathrm{ft}^{2}$, and provide an absolute reference pressure measurement for the entire system. Both units are saturated below a $50,000-\mathrm{ft}$ altitude, which is acceptable because the experiment is designed for high altitude between 70,000 and $100,000 \mathrm{ft}$. The data from all transducers are sampled and sent by telemetry to the ground at a rate of $25 \mathrm{~Hz}$. The pressure system mounted in and on the right wing including rakes, probes, and transducers weighs less than $30 \mathrm{lb}$.

\section{Uncertainty Analysis}

A preliminary measurement uncertainty analysis was performed on the pressure system and is summarized with a discussion of the bias error for the calculation of lift. This analysis is based on the general uncertainty analysis of Coleman and Steele. ${ }^{20}$ The pressure coefficient $\left(C_{p}\right)$ can be defined in terms of measured quantities as follows:

$$
\begin{aligned}
C_{p}= & \frac{P-P_{s}}{\bar{q}}=\frac{P-P_{s}}{0.7 P_{s} \mathrm{M}^{2}} \\
= & \frac{P-P_{s}}{0.7 P_{s} \frac{2}{\gamma-1}\left[\left(\frac{P_{T}}{P_{s}}\right)^{\frac{\gamma-1}{\gamma}}-1\right]}
\end{aligned}
$$

where $P$ is the port pressure, $\bar{q}$ is the dynamic pressure, $M$ is the Mach number, and $\gamma$ is the ratio of specific heats.

Treating $P-P_{s}, P_{s}$, and $P_{T} / P_{s}$ as measured quantities, the general uncertainty equation is 


$$
\begin{aligned}
\left(\frac{U_{C_{p}}}{C_{p}}\right)^{2}= & \left(\frac{U_{P-P_{s}}}{P-P_{s}}\right)^{2}+\left(\frac{U_{P_{S}}}{P_{S}}\right)^{2} \\
& +\left(\frac{U_{P_{T} / P_{s}} \frac{\gamma}{\gamma-1}\left(\frac{P_{T}}{P_{s}}\right)^{\frac{\gamma-1}{\gamma}}}{\left[\left(\frac{P_{T}}{P_{s}}\right)^{\frac{\gamma-1}{\gamma}}-1\right]}\right)^{2}
\end{aligned}
$$

where $U$ is the uncertainty for the subscript variable.

For a $C_{p}=1$ and a flight condition of Mach 0.65 and $100,000 \mathrm{ft}$ altitude, the expected pressure quantities and their associated bias errors from the manufacturer's specifications are

$$
\begin{aligned}
P-P_{s} & =7.49 \pm 0.14 \mathrm{lb} / \mathrm{ft}^{2} \\
P_{s} & =22.7 \pm 0.072 \mathrm{lb} / \mathrm{ft}^{2} \\
P_{T} / P_{s} & =1.33 \pm 0.0012 \mathrm{lb} / \mathrm{ft}^{2}
\end{aligned}
$$

Substituting these quantities into the uncertainty equation (2) yields the pressure coefficient bias error of

$$
C_{p}=1 \pm 0.02 \text { (or } \pm 2 \% \text { ) }
$$

For a $C_{p}=-0.5$, the result is

$$
C_{p}=-0.5 \pm 0.02(\text { or } \pm 4 \%)
$$

The bias error for the section lift coefficient,

$$
C_{l}=\frac{1}{c} \int_{0}^{c}\left(C_{p_{l}}-C_{p_{u}}\right) d x
$$

is expected to be

$$
\left.C_{l}=0.9 \pm 0.028 \text { (or } \pm 3 \%\right)
$$

where $c$ is the airfoil chord and the subscripts $l$ and $u$ refer to the lower and upper surface, respectively.

A similar bias error analysis for the calculation of the section drag coefficient for the flight condition of Mach 0.65 and 100,000-ft altitude yields

$$
C_{d}=0.02 \pm 0.004 \text { (or } \pm 20 \% \text { ) }
$$

The percentage of bias error decreases as the sailplane descends to lower altitudes because the measured pressures become larger. For a $C_{p}=1$ and a flight condition of Mach 0.65 and $70,000-\mathrm{ft}$ altitude, the expected bias errors are

$$
\begin{aligned}
& \left.C_{p}=1 \pm 0.005 \text { (or } \pm 0.5 \%\right) \\
& C_{l}=0.9 \pm 0.006 \text { (or } \pm 0.7 \% \text { ) } \\
& C_{d}=0.01 \pm 0.0005 \text { (or } \pm 0.5 \% \text { ) }
\end{aligned}
$$

Marchman $^{21}$ states that "[d]rag has always been the most difficult aerodynamic force to measure and the low drag forces occurring in low Reynolds number flows make the problem even more difficult." The APEX experiment is not immune to these difficulties. The average wake deficit pressure is estimated to be on the order of $1 \mathrm{lb} / \mathrm{ft}^{2}(\mathrm{M}=0.65$, altitude $=100,000 \mathrm{ft})$ and $5 \mathrm{lb} / \mathrm{ft}^{2}(\mathrm{M}=0.65$, altitude $=70,000 \mathrm{ft})$. The range of the differential pressure transducer used to measure the wake deficit pressure is $\pm 52 \mathrm{lb} / \mathrm{ft}^{2}$ and has an accuracy of \pm 0.1 percent full scale. A smaller range transducer to lower the bias percentage error was not available that would satisfy the APEX design constraints of size and weight. The transducer is capable of remote zero-point calibration by applying a single reference pressure to both sides of the differential. This zero-point calibration will be performed before release from the balloon at $100,000 \mathrm{ft}$ altitude and just after the experimental measurements are completed at $70,000 \mathrm{ft}$ altitude.

A comparison was made by Marchman ${ }^{21}$ of the drag coefficient measurements on a Wortmann FX63-137 airfoil performed by three different research facilities. The results show differences of more than 50 percent in the measurement of drag coefficient for similar test conditions. Although the section drag coefficient bias error range of \pm 20 to \pm 5 percent is large, it is not unreasonable given the difficulties of the measurement. The 5-percent error at 70,000 $\mathrm{ft}(\operatorname{Re}=700,000)$ is more representative of measured in-flight drag errors at high Reynolds numbers. For example Arnaiz ${ }^{22}$ measured the in-flight drag on the XB-70 airplane accurate to \pm 6.5 percent at Reynolds numbers ranging from $1,000,000$ to $3,000,000$ per foot.

Other errors are associated with the accuracy of the pressure system measurements. The displacement effects associated with the pitot probe disturbing the local flow field can affect the accuracy of the probe total pressure measurement. Montoya et al. ${ }^{23}$ discuss these 
displacement effects in detail. Allen ${ }^{24}$ reports a survey of pitot probe displacement corrections for free shear flows of approximately 18 percent of the probe diameter. The APEX trailing rake pitot probes have a 0.07-in. diameter and the airfoil wake height is expected to be 3 to 5 in. depending on flight conditions. The displacement effects of the pitot probe total pressure measurements are less than 0.2 percent.

Lag times in the pneumatic tubing between the pressure port and the transducer can also be a large source of error under dynamic conditions. The low static pressure at $100,000 \mathrm{ft}$ altitude, $23 \mathrm{lb} / \mathrm{ft}^{2}$, can cause large pneumatic lag times. Laboratory tests and calculations performed at NASA Dryden show that the lag times are less than $1.5 \mathrm{sec}$. Lag times are reduced as the sailplane descends in altitude because lag times are inversely proportional to pressure. Lag times should not pose a significant source of error as flight simulations show that a flight condition of constant Mach number and constant lift coefficient for the sailplane can be maintained for 5 to $10 \mathrm{sec}$.

It is difficult to estimate how much pressure measurement uncertainty is a result of the threedimensional effects of turbulence. Large-scale turbulent vortical structures and vortex shedding, if present, may significantly affect the accuracy of the static and pitot pressure measurements. The pneumatic tubing lags dampen the dynamic response of the pressure measurements. Pressure variations caused by the large vortical structures moving across the airfoil flow field are not detected and their effects on a time averaged or lagged static and pitot pressure measurements are uncertain.

Large-scale vortical structures also present uncertainties caused by changes in the local flow direction. As shown by Mueller, ${ }^{1}$ the accuracy of trailing rakes to determine drag is severely compromised in flows with large-scale vortical structures resulting from the changing flow direction. The changing flow direction may also affect a static pressure measurement in similar fashion as a vortex passes over a static port on the surface of the airfoil. The presence of large-scale turbulent vortical structures and vortex shedding is detected from the hot-film measurements.

The experiments of Batill and Mueller ${ }^{25}$ and Guglielmo and Selig $^{26}$ suggest that spanwise variations may exist in the separation bubble dynamics caused by the three-dimensional effects of turbulence. Bastedo and Mueller ${ }^{27}$ measured a significant spanwise variation in a laminar separation bubble due to wing tip vortices. The APEX wing incorporates a 2-deg linear washin to reduce spanwise effects of the wing tip vortex and to provide a more uniform $C_{l}$ distribution over the experimental area of the wing.

Random errors are often difficult to separate from the natural in-flight pressure fluctuations. Random errors are believed to be largely caused by RFI and EMI. Natural pressure fluctuations are caused by atmospheric turbulence, aircraft vibration, and changes to flight conditions such as angle of attack and angle of sideslip. Before releasing the sailplane from the high-altitude balloon, a series of pressure data samples is taken and sent by telemetry to the ground. An assumption is that, while the sailplane is suspended under the balloon, the air relative to the sailplane is still and there are no natural pressure fluctuations. All fluctuations in the prelaunch data samples, therefore, are assumed to be random errors. Any additional random fluctuations that occur in flight are assumed to be natural pressure fluctuations occurring over the surface of the airfoil. In addition, the pneumatic tubing lags dampen all highfrequency natural pressure fluctuations.

The difficulty in obtaining accurate pressure measurements is realized when considering all the possible errors (bias, nonlinear pitot effects, pneumatic lags, large-scale vortical structures, spanwise variations, and random). The presence of large-scale vortical structures severely compromises the measurement accuracy. However, identifying flight regimes that contain large-scale vortical structures is an important part of the experiment. As will be discussed later, these regimes are highly undesirable because of their associated large drag. The APEX experiment is expected to significantly increase the understanding of low-Reynolds-number airfoils at high altitude and provide data for validation of airfoil design codes. The uncertainties in the experimental data will be properly accounted for.

\section{$\underline{\text { Hot-Film Measurement System }}$}

A multi-element hot-film strip is mounted over the APEX-16 airfoil. The hot-film strip measures the state of the boundary layer (i.e., laminar boundary layer, laminar separation, bubble region, turbulent reattachment, turbulent boundary layer, turbulent separation, and vortex shedding) and the frequency of the Tollmien-Schlichting instability waves in the separation bubble. The strip consists of 50 hot films on the top surface in 2-percent chord increments starting at 
zero-percent chord. The hot films are spaced approximately $0.75 \mathrm{in}$. apart. In addition, four hot films are placed on the bottom surface at 10-, 30-, 60-, and 90-percent chord. This hot-film-strip configuration is used for the initial flights. After the separation bubble is located for the APEX flight regime, the strip is replaced with a denser strip concentrated in the area of the separation bubble (approximately 50 evenly spaced hot films on a 15-percent chord length).

The desire to obtain valid hot-film anemometry data at frequencies up to $10 \mathrm{kHz}$ combined with the weight and packaging limitations significantly influenced the design. The APEX telemetry system cannot handle these high data transfer rates for the large number of channels. Therefore, the data are stored on board in random access memory and later, after the high-altitude tests are completed, sent by telemetry to the ground at lower data transfer rates. The hot-film data are split into two components: a DC component and an AC component. The DC component is sampled at $200 \mathrm{~Hz}$ and sent by telemetry to the ground in real time. The $\mathrm{AC}$ component is sampled in $1-\mathrm{sec}$ data intervals at 20 to $25 \mathrm{kHz}$ and stored in memory. The system is capable of storing up to ten 1-sec data intervals during a flight. The system is commanded from the ground uplink to begin storing a 1-sec data interval of AC data. In summary, all 54 hot films are sampled for their DC component at $200 \mathrm{~Hz}$ as the sailplane descends from 100,000 to $70,000 \mathrm{ft}$. The 54 hot films are sampled for their $\mathrm{AC}$ component at 20 to $25 \mathrm{kHz}$ in 1-sec data intervals for up to 10 intervals as the sailplane descends from 100,000 to $70,000 \mathrm{ft}$.

Figure 8 shows a schematic of the hot-film anemometry and data acquisition system. The anemometry is a temperature-compensated system developed by Chiles. ${ }^{28}$ The anemometry incorporates a temperature sensor located in proximity to the hot film as part of the Wheatstone bridge. The temperature sensor corrects the sensitivity of the anemometry circuit to changes in the average adiabatic wall temperature caused by changes in flight condition. The system also incorporates automatic gain ranging that automatically adjusts the $\mathrm{AC}$ signal gain so that the peak-to-peak signal is approximately 50 percent of the total signal range. Each hot film has an anemometry circuit, a signal conditioning circuit that includes the automatic gain ranging, and a $10-\mathrm{kHz}$ low-pass filter to prevent antialiasing.

The hot-film signals are multiplexed in groups of four, to a data logger and A/D converter (fig. 8). The data are then transferred to the pulse code modulation (PCM) encoder at lower data rates to be sent by telemetry to the

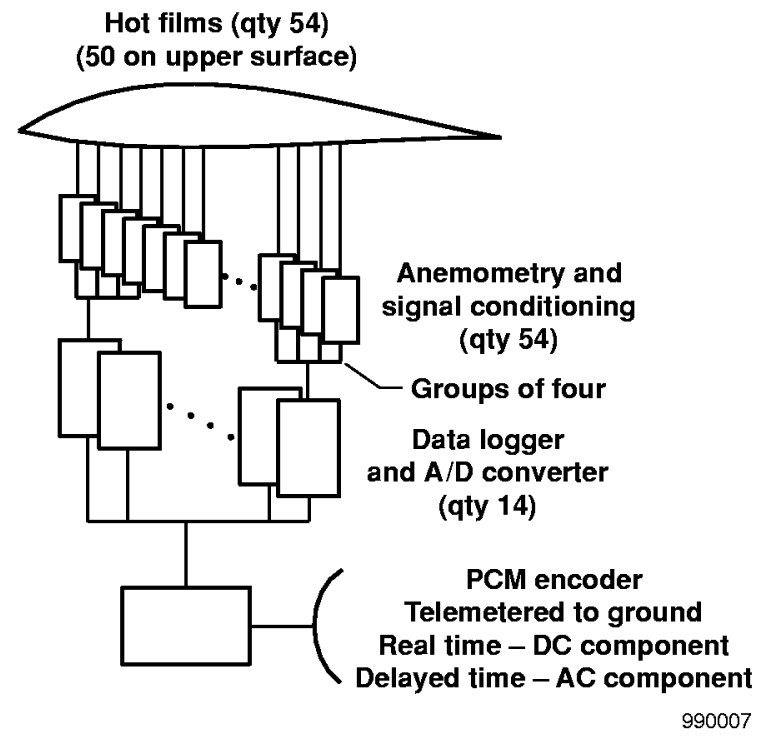

Figure 8. Hot-film anemometry system for the rightwing test section.

ground after the high-altitude portion of the flight is completed. The hot-film system, excluding the PCM, is estimated to weigh $20 \mathrm{lb}$ and sits in the right wing under the hot-film sheet.

Spectral analysis is the primary means of data reduction of the hot-film data. Preliminary calculations show that a $1-\mathrm{sec}$ interval of data sampled at 20 to $25 \mathrm{kHz}$ is adequate to resolve the spectral content between $50 \mathrm{~Hz}$ and $10 \mathrm{kHz}$. This spectral content should be adequate for determining the flow field on the upper surface of the APEX airfoil. The detection of phase reversal and a significant change in power spectral density is expected to be the signature of laminar separation and the beginning of the separation bubble. Phase reversal of low-frequency spectra has been shown by Mangalam et al. ${ }^{29}$ to be an effective method of detecting laminar separation.

Turbulent reattachment of the bubble is detected in the same manner as laminar separation-by phase reversal and a significant change in power spectral density caused by turbulence. The presence of vortex shedding is detected by performing both auto and cross power spectral density analysis on the hot films aft of the separation bubble. The detection of a significant increase in spectra in a specific frequency range and a consistent phase lag between the hot films is a signature of vortex shedding. 
The Tollmien-Schlichting instability wave frequencies in the free shear layer of the bubble is detected by spectral analysis of hot films inside the separation bubble and possibly by hot films just upstream of the separation bubble. The separated flow instability research of Dovgal et al. ${ }^{4}$ show that instability waves, which cause transition, can be generated either upstream of the separation point or downstream of the separation point in the free shear layer. Their experiments show that harmonic disturbances causing transition exist inside the separation bubble. They discuss the concept of feedback interactions whereby instability waves are convected forward to the separation point as the flow circulates inside the bubble.

At present, hot films have not been used to detect Tollmien-Schlichting instability frequencies and the bubble instabilities are assumed to be detected at the surface of the airfoil. The computational fluid dynamics analysis and Orr-Sommerfeld analysis performed by Tatineni and Zhong, 8 suggest that the TollmienSchlichting instability waves occur at approximately $1000 \mathrm{~Hz}$. A significant increase in the spectral density in this frequency range for hot films in the separation bubble is, therefore, a measure of the TollmienSchlichting instability frequencies.

\section{$\underline{\text { Uncertainty Analysis }}$}

Before actual flight, any estimate of the data quality from the hot-film system is difficult. The goal is a signal-to-noise ratio of 20 or greater. To reduce RFI and EMI noise, the hot-film strip comprises three laminated sheets. The top and bottom sheets are ground planes to shield the hot-film leads in the middle sheet. Twisted and shielded cabling are used for connections. The anemometry cards are packaged with ground plane protection.

The aircraft power is filtered to ensure that the anemometry signals are not contaminated by power fluctuations. Special preflight ground test equipment is being developed that selectively blows both laminar and turbulent air over each hot film, matching the Nusselt number expected in flight. This equipment allows the individual hot-film signals to be compared and used to qualify, to first order, signal intensities between hot films. In addition, while the sailplane is suspended under the balloon, a 1-sec data interval is taken to assess noise levels.
Vane, Total Temperature, and Accelerometer

Measurements

A pair of identical vanes is being developed for APEX to measure the angle of attack and angle of sideslip. The vanes will be calibrated to within $\pm 0.25 \mathrm{deg}$ to the local flow field angle of attack. The vanes will be mounted on a boom, located one-fuselage diameter in front of the nose of the aircraft. The position (upwash) error at this location, the difference between the local flow field angle of attack and the true angle of attack, can vary substantially. This difference in angle of attack is caused by the upwash from the boom, wings, and fuselage. The position error is expected to be a function of lift coefficient and Mach number. The error is estimated from the results of Rogallo ${ }^{30}$ to be $0.3 \mathrm{deg}$ at $C_{l}=0.3$ and $1.2 \mathrm{deg}$ at $C_{l}=1.2$ for a Mach number of 0.6. A three-dimensional potential flow calculation of the APEX flow field provides a correction for the position error of angle of attack and angle of sideslip.

The vane is currently being designed and fabricated and is expected to weigh approximately $10 \mathrm{gm}$ to lower the moment of inertia and increase the vane response time. Preliminary near sea level wind-tunnel tests show that the vane damping ratios are between 0.2 to 0.33 and the natural frequencies are between 7 to $17.5 \mathrm{~Hz}$ as the dynamic pressure is varied between 18 and 50 KEAS. The in-flight time response of the vane is expected to be approximately $1.5 \mathrm{sec}$ and is calculated by extrapolating the near sea level data to a flight condition of $40 \mathrm{KEAS}$ at $100,000 \mathrm{ft}$ by the method described in Barna and Crossman. ${ }^{31}$ The $1.5-\mathrm{sec}$ time response is adequate for steady-state measurements as flight simulations show that a flight condition of constant Mach number and constant lift coefficient for the sailplane can be maintained for 5 to $10 \mathrm{sec}$.

The total temperature measurement is performed with an adaptation to a standard Rosemount (Burnsville, Minnesota) RTD total temperature probe. The RTD sensor is replaced with a Thermometrics (Edison, New Jersey) thermistor to increase the time response of the sensor. Friehe and Khelif $^{32}$ developed this adaptation. The in-flight response time is expected to be approximately $1 \mathrm{sec}$ and the accuracy is expected to be $\pm 0.5^{\circ} \mathrm{F}$. The sensor has been fabricated but has not been tested and calibrated.

Three Endevco (San Juan Capistrano, California) piezoelectric accelerometers are mounted inside the wing to the upper surface at chord locations of 20,50 , and 80 percent. The accelerometers are sampled at 
20,000 samples per second and have a frequency range of 1 to $10,000 \mathrm{~Hz}$ and an accuracy of $\pm 0.05 \mathrm{~g}$. A spectral analysis is performed on the accelerometer data and compared with the hot-film spectral analysis to explore any aeroelastic effects that may affect laminar-toturbulent transition.

\section{Predicted Airfoil Performance}

The prediction of low-Reynolds-number airfoil performance is a formidable task that involves correctly modeling several flow phenomena as was shown in figure 2. Modeling the inviscid flow field including the presence of shock waves is generally considered the first step to determining the pressure distribution over the surface of the airfoil. The viscous flow field is composed of the boundary layer, laminar separation, laminar free shear layer, transition to turbulence in the free shear layer, turbulent free shear layer, reattachment of the turbulent free shear layer, and turbulent boundary layer. In addition turbulent separation and laminar bubble separation, known as bubble bursting, are important physical characteristics to be modeled. The interaction between the inviscid and viscous flow fields can be significant. The presence of the separation bubble alters the effective shape of the inviscid airfoil. The classic assumption that pressure is constant across the boundary layer may not be valid across the separation bubble. In addition, boundary layers become large at low Reynolds numbers increasing the boundary displacement thickness, which can have an appreciable effect on the inviscid pressure distribution.

The design and initial predictions of the APEX-16 airfoil are performed with the MSES code. The MSES airfoil design code uses the Euler equations to solve the inviscid flow field coupled with a two-equation dissipation integral method to solve for the viscous boundary layer. The transition location is determined via the amplitude ratio $\left(e^{n}\right)$ method, using growth rates that are precomputed from solutions of the Orr-Sommerfeld equation and correlated to the local shape factor parameter and momentum thickness Reynolds number. No compressibility corrections are employed partly because of the large uncertainty in the appropriate critical amplification parameter, $n_{c r i t}$, for this highsubsonic-Mach-number and low-Reynolds-number flight regime. A value for $n_{\text {crit }}$ of 12 was assumed for design of the APEX-16 airfoil. Liebeck ${ }^{33}$ uses an earlier version of the MSES code, ISES, and finds that the predictions for low-Reynolds-number airfoils are reliable and accurate for low Mach numbers. One goal of the APEX experiment is to determine whether MSES remains reliable in the high-subsonic-Mach-number and
low-Reynolds-number flight regime and what $n_{\text {crit }}$ values are appropriate.

Figures 9 through 11 present the predicted drag polars and lift curves for the APEX-16 airfoil for the chord Reynolds numbers of 200,000, 300,000, and 500,000, respectively, from the MSES code. The first apparent characteristic in the figures is the decrease in maximum lift coefficient with increasing Mach number. This decrease results from the separation of the turbulent boundary layer from the airfoil as the Mach number increases. The maximum lift coefficient decreases and the drag coefficient increases as the Reynolds numbers decrease. This result is expected as the separation bubbles become larger with lower Reynolds numbers, which decreases the overall performance of the airfoil. The lift curve slope is relatively unaffected by Mach number and Reynolds number except near stall. The slope of the pitching moment coefficients with angle of attack is also relatively unaffected by Mach number and Reynolds number. The predicted transition location, $x_{T R}$, versus lift coefficient are also presented in the figures. The transition location on the upper surface moves forward and the transition location on the lower surface moves aft with increasing lift coefficient or angle of attack $(\alpha)$.

Figure 12 presents the predicted drag polars and lift curves for various chord Reynolds numbers between 200,000 and 2,000,000 for a 0.6 Mach number. The decreasing airfoil performance with lower Reynolds numbers is again apparent. An interesting feature of the figure is that the pitching moment increases with lower Reynolds numbers. Examining the data of McGhee et al., ${ }^{34}$ the reverse would be expected. Their data show that, with lower Reynolds numbers, bubble reattachment occurs farther aft on the airfoil, which delays the pressure recovery on the upper surface. This effect results in decreasing the pitching moment. Figure 13 shows the APEX-16 airfoil predicted pressure distribution for a Reynolds number of 200,000 and 300,000 at Mach 0.65. In the figure the bubble reattachment is predicted to move aft with lower Reynolds numbers and is in agreement with the data of McGhee et al. ${ }^{34}$ The reattachment point is shown in the figure by the point of discontinuous change in slope of the pressure recovery on the upper surface. With lower Reynolds numbers, however, the separation point moves forward and the overall pressure on the upper surface increases. The point of separation is just after the point of minimum pressure on the upper surface as shown in the figure. The overall gain in upper surface pressure results in increasing the pitching moment with lower Reynolds numbers. 

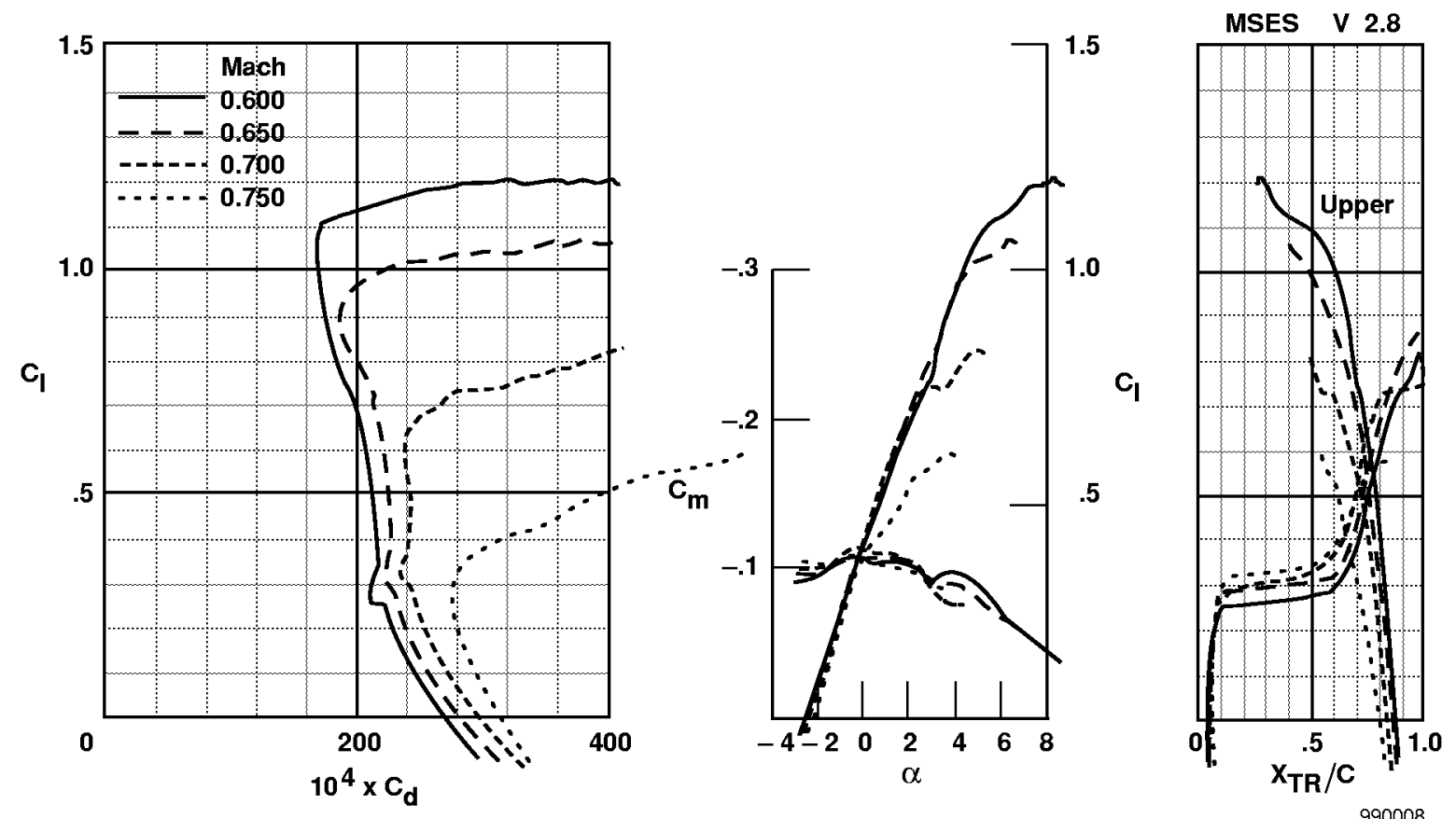

Figure 9. MSES prediction for APEX-16 airfoil at $\operatorname{Re}=200,000$.
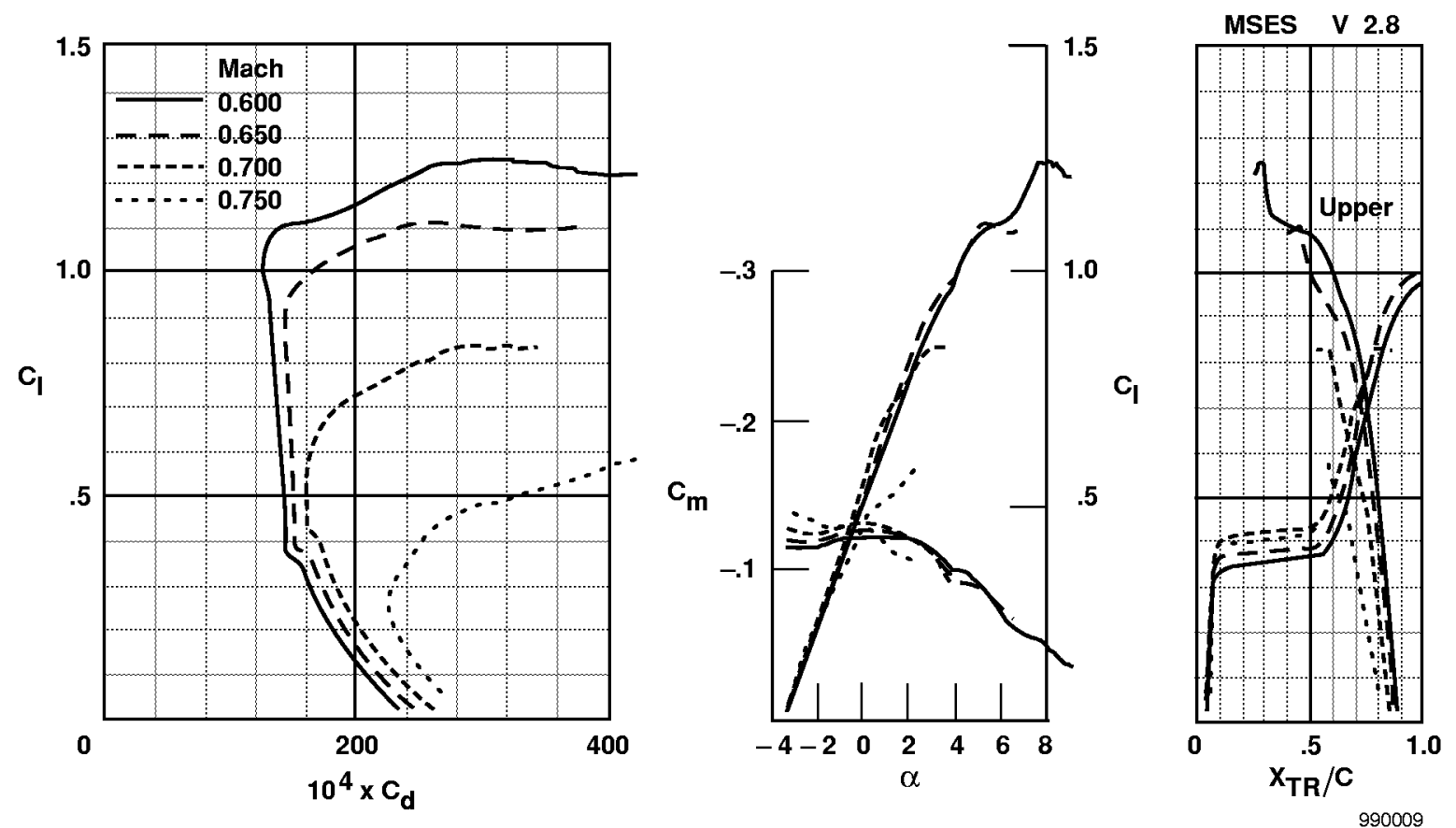

Figure 10. MSES prediction for APEX-16 airfoil at $\operatorname{Re}=300,000$. 

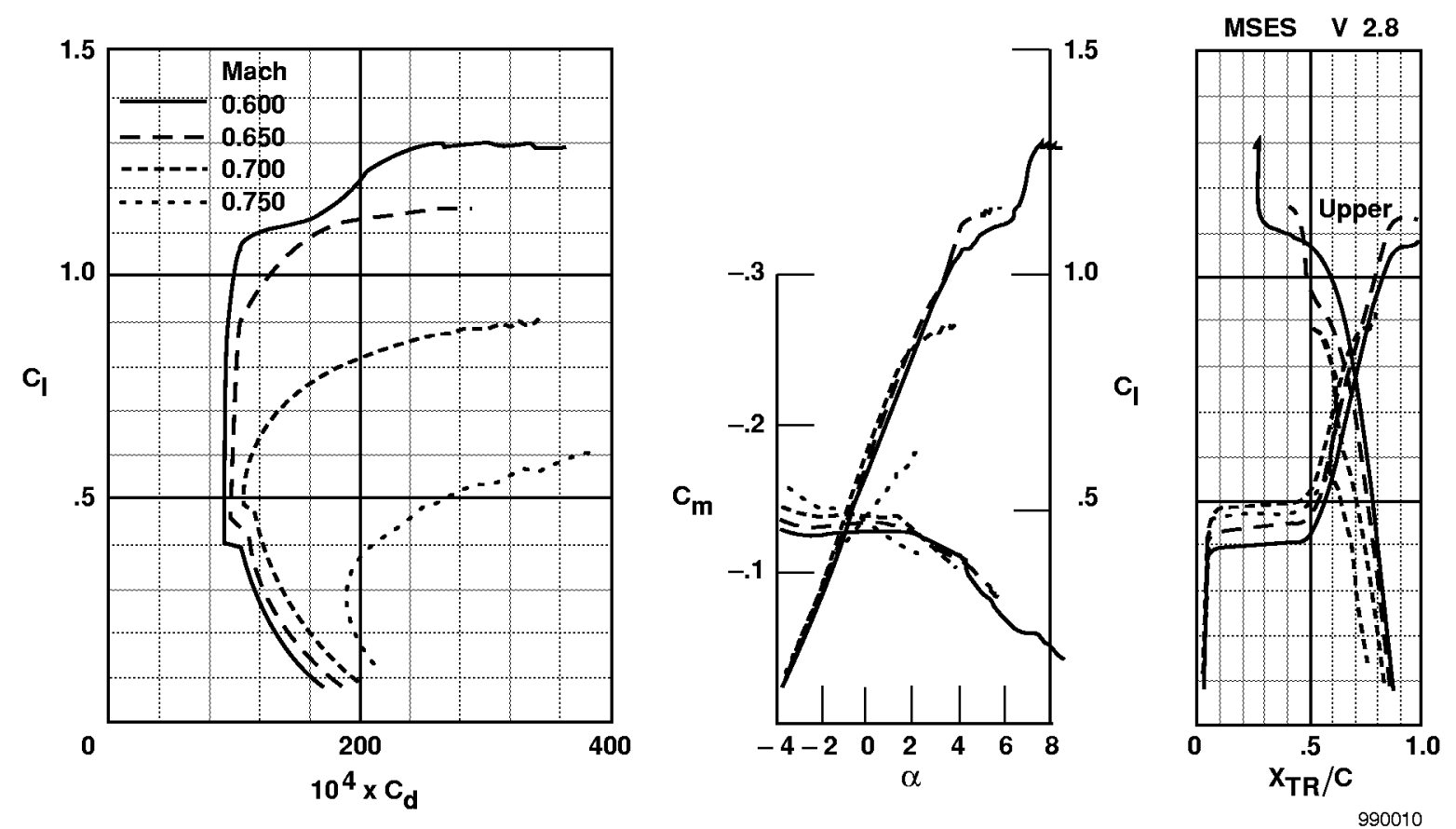

Figure 11. MSES prediction for APEX-16 airfoil at $\operatorname{Re}=500,000$.
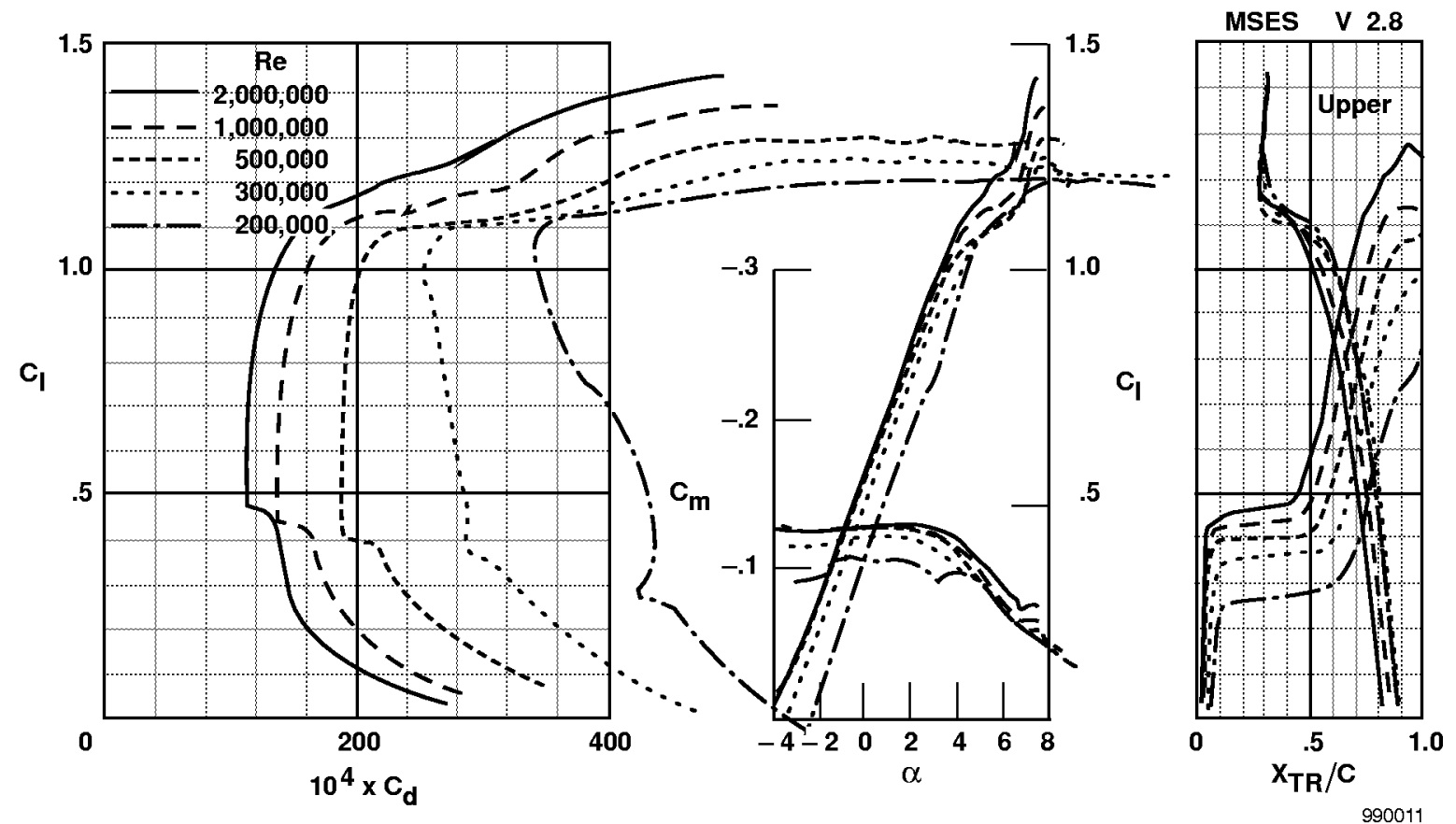

Figure 12. MSES prediction for APEX-16 airfoil at $\mathrm{M}=0.6$. 


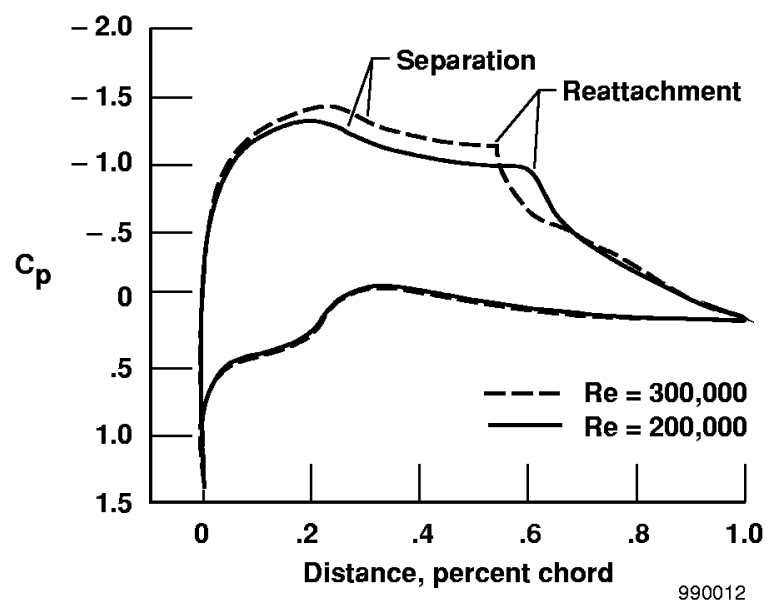

Figure 13. MSES prediction of the pressure distribution over the APEX-16 airfoil $(\mathrm{M}=0.65$; $\alpha=3.5 ; \operatorname{Re}=200,000$ and 300,000 ).

A time-accurate Navier-Stokes analysis was performed on the APEX-16 airfoil by Tatineni and Zhong. 8,9 Their analysis predicts that the separation bubble on the upper surface of the airfoil is unstable. The separation bubble is predicted to periodically shed at about $950 \mathrm{~Hz}$ for the subsonic flight condition of Mach 0.5, Reynolds number 200,000, and an angle of attack of $4 \mathrm{deg}$. The flow field over the upper surface is predicted to become very erratic as the Mach number is increased into the transonic range, as shown in figures 14 and $15^{* *}$ The predicted interaction between the shock waves and the shedding vortices, as seen in the figures, has a profound effect on the flow field and the airfoil section lift coefficient. The section drag also increases substantially. A time-accurate Navier-Stokes analysis was also performed at NASA Dryden on the APEX-16 airfoil. Figure 16 shows the predicted unsteady separated vortex region on the aft upper surface of the airfoil. The results are similar to those of Tatineni and Zhong. ${ }^{8,9}$

The vortex shedding criterion suggested by Pauley et al. ${ }^{5}$ is

$$
P_{\max }=\frac{\theta_{\text {sep }}^{2}}{v}\left(\frac{d u}{d x}\right)_{\max } \approx-0.24
$$

where $P_{\text {max }}$ is a dimensionless pressure gradient proposed by Gaster, ${ }^{35} \theta_{\text {sep }}$ is the boundary layer momentum thickness at separation, $v$ is the kinematic viscosity, and $(d u / d x)_{\max }$ is the maximum velocity

${ }^{* * *}$ Tatineni, Mahidhar and Xiaolin Zhong, "Numerical Simulation of Unsteady Low-Reynolds-Number Transonic Separated Flows Over the APEX Airfoil, APEX Critical Design Review," NASA Diyden, 1998, unpublished. Grant NCC 2-374, UCLA Flight Research Center.

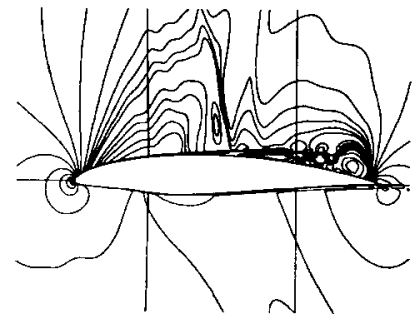

Frame 1

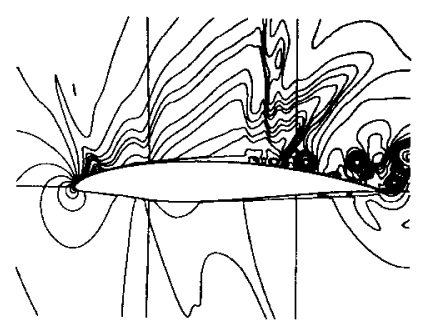

Frame 4

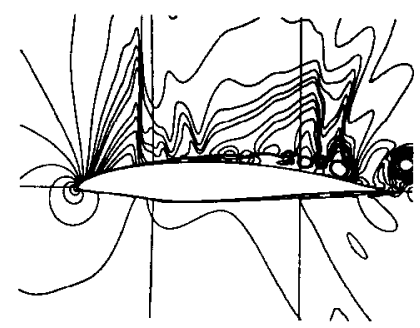

Frame 2

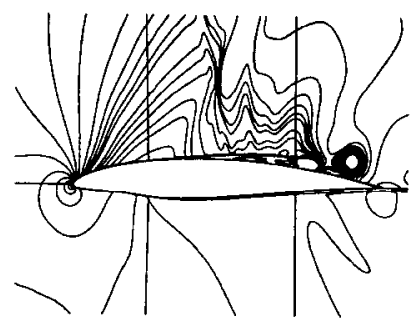

Frame 5

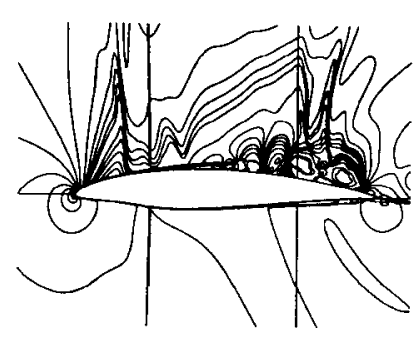

Frame 3

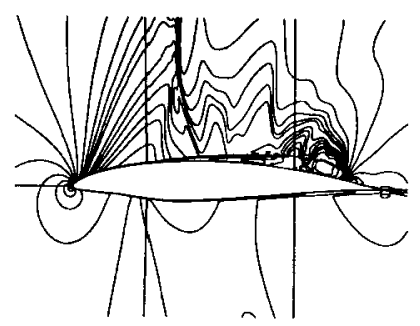

Frame 6

990013

Figure 14. Unsteady variation of pressure contours for the transonic APEX-16 airfoil $(M=0.65 ; \operatorname{Re}=200,000$; $\alpha=4^{\circ}$ ). Time interval between frames is $0.0016 \mathrm{sec}$. 


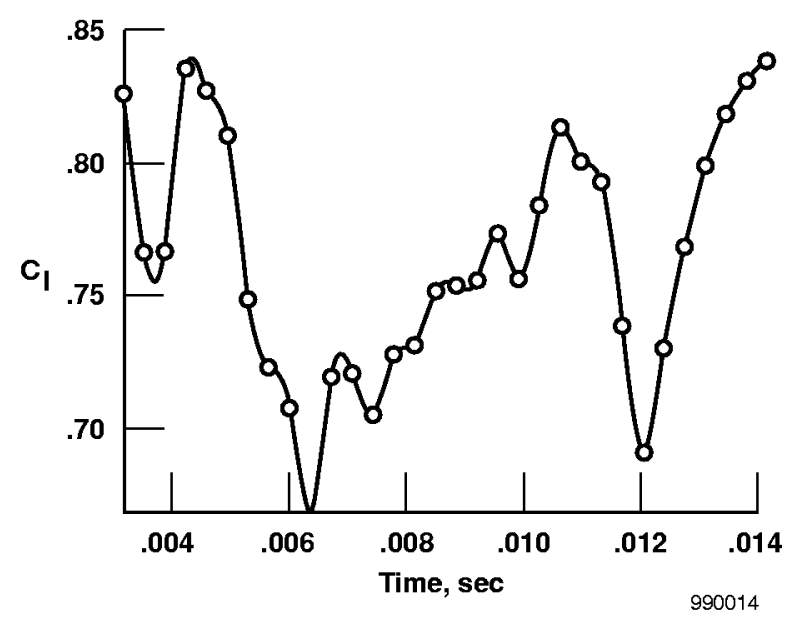

Figure 15. Unsteady variations of average section lift coefficient for the transonic APEX-16 airfoil $(\mathrm{M}=0.65$; $\operatorname{Re}=200,000 ; \alpha=4^{\circ}$ ).

gradient. The shedding criterion for the APEX-16 airfoil at a flight condition of Mach 0.65 , Reynolds number 200,000 , and an angle of attack of $4 \mathrm{deg}$ is

$$
P_{\text {max }}=-1.47
$$

Therefore, unstable shedding vortices should be expected on the APEX-16 airfoil according to the suggested shedding criterion.

The stability of the separation bubble has a large effect on the airfoil predicted performance. The MSES code, based on stable bubble calculations, predicts a lift coefficient of 0.96 at the flight condition of Mach 0.65 , Reynolds number 200,000 , and an angle of attack of $4 \mathrm{deg}$. The Navier-Stokes code predicts an average section lift coefficient of 0.76 for the same flight condition. The Navier-Stokes analysis assumed laminar flow. The effects of turbulence on the stability of the separation bubble are uncertain. Gruber et al. ${ }^{36}$ performed a direct numerical simulation that showed that an amplified Tollmien-Schlichting wave in the free shear layer of a separation bubble develops into a large vortical structure. Whether the intensity of these vortical structures is large enough to maintain the structure as transition into turbulence occurs is unknown. These large vortical structures may be analogous to large-scale turbulent eddies that are quickly broken up in the turbulent flow field through vortex stretching and the three-dimensional effects of turbulent flow.
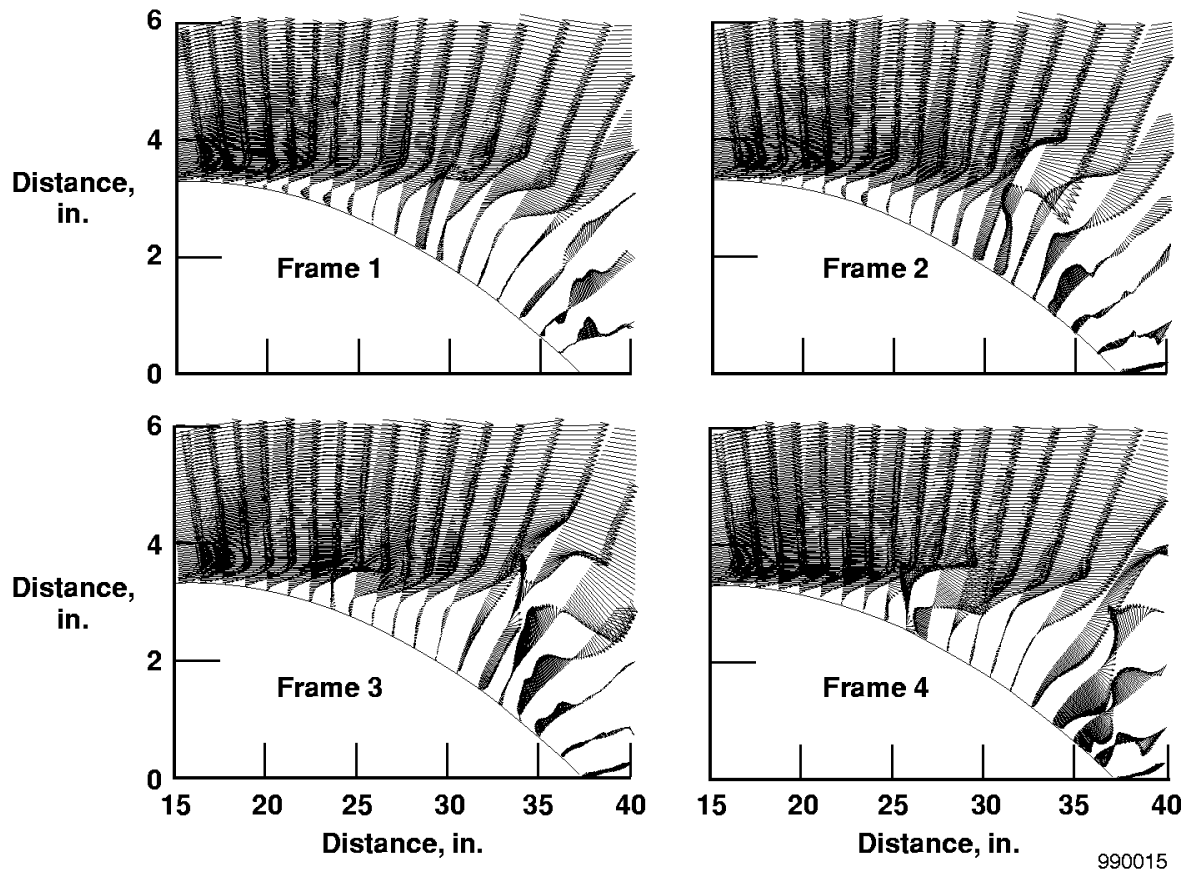

Figure 16. Unsteady variation of velocity vectors for the aft section of the APEX upper surface. Plot sequence time interval is $0.0015 \mathrm{sec}\left(\mathrm{M}=0.65 ; \operatorname{Re}=200,000 ; \alpha=4^{\circ}\right)$. 


\section{Concluding Remarks}

The purpose of the APEX experiment is to increase the understanding of low-Reynolds-number airfoils in a low-turbulence flight environment. The APEX experiment regime is for altitudes between 70,000 and $100,000 \mathrm{ft}$, Mach numbers between 0.5 and 0.65 , and Reynolds numbers between 100,000 and 700,000. The following characteristics of the airfoil are to be determined:

1. Section lift.

2. Section drag.

3. Location of the separation bubble.

4. Vortex shedding characteristics.

5. Tollmien-Schlichting frequencies.

\section{Acknowledgments}

The authors express their gratitude to the APEX project members developing the sailplane and experiment. We gratefully acknowledge Albion Bowers (NASA Dryden Flight Research Center, Edwards, California) and Rick Howard (Naval Postgraduate School, Monterey, California) for their many helpful discussions.

\section{References}

${ }^{1}$ Mueller, T. J., "Low Reynolds Number Vehicles," AGARD-AG-288, 1985.

${ }^{2}$ LeBlanc, P., R. Blackwelder, and R. Liebeck, "A Comparison Between Boundary Later Measurements in a Laminar Separation Bubble Flow and Linear Stability Theory Calculations," in Low Reynolds Number Aerodynamics Conference Proceedings, 1989, pp. 189-205.

${ }^{3}$ Howard, R. M. and D. W. Kindelspire, "Freestream Turbulence Effects on Airfoil Boundary-Layer Behavior at Low Reynolds Numbers," J. Aircraft, vol. 27, no. 5, May 1990, pp. 468-470.

${ }^{4}$ Dovgal, A. V., V. V. Kozlov, and A. Michalke, "Laminar Boundary Layer Separation: Instability and Associated Phenomena," Prog. Aerospace Sci., vol. 30, 1994, pp. 61-94.

${ }^{5}$ Pauley, Laura L., Parviz Moin, and William C. Reynolds, "The Structure of Two-Dimensional
Separation," J. Fluid Mech., vol. 220, 1990, pp. 397411.

${ }^{6}$ Ripley, Matthew D. and Laura L. Pauley, "The Unsteady Structure of a Two-Dimensional Steady Laminar Separation," Phys. Fluids A., vol. 5, no. 12, Dec. 1993, pp. 3099-3106.

${ }^{7}$ Muti Lin, J. C. and Laura L. Pauley, "Low-ReynoldsNumber Separation on an Airfoil," AIAA Journal, vol. 34, no. 8, Aug. 1996, pp. 1570-1577.

${ }^{8}$ Tatineni, M. and X. Zhong, "Numerical Simulation of Unsteady Low-Reynolds-Number Separated Flows Over Airfoils," AIAA 97-1929, July 1997.

${ }^{9}$ Tatineni, Mahidhar and Xiaolin Zhong, "Numerical Simulations of Unsteady Low-Reynolds-Number Flows Over the APEX Airfoil," AIAA 98-0412, Jan. 1998.

${ }^{10}$ Drela, Mark, "Transonic Low-Reynolds Number Airfoils," J. Aircraft, vol. 29, no. 6, Nov.-Dec. 1992, pp. 1106-1113.

${ }^{11}$ Reshotko, E., "Environment and Receptivity," in Special Course on Stability and Transition of Laminar Flow, AGARD-R-709, 1984, p. 4-1.

${ }^{12}$ Dryden, H. L. and A. M. Kuethe, Effect of Turbulence in Wind Tunnel Measurements, NACA Report No. 342, 1929.

${ }^{13}$ Dryden, Hugh L., G. B. Schubauer, W. C. Mock, Jr., and H. K. Skramstad, Measurements of Intensity and Scale of Wind-Tunnel Turbulence and Their Relation to the Critical Reynolds Number of Spheres, NACA Report No. 581, 1937.

${ }^{14}$ Fisher, David F. and N. Sam Dougherty, Jr., InFlight Transition Measurement on a $10^{\circ}$ Cone at Mach Numbers From 0.5 to 2.0, NASA TP-1971, June 1982.

${ }^{15}$ Murray, James, Timothy Moes, Ken Norlin, Jeffrey Bauer, Robert Geenen, Bryan Moulton, and Stephen Hoang, Piloted Simulation Study of a Balloon-Assisted Deployment of an Aircraft at High Altitude, NASA TM-104245, Jan. 1992.

${ }^{16}$ Giles, Michael B. and Mark Drela, "TwoDimensional Transonic Aerodynamic Design Method," AIAA Journal, vol. 25, no. 9, Sept. 1987, pp. 1199-1206.

${ }^{17}$ Drela, Mark and Michael B. Giles, "ViscousInviscid Analysis of Transonic and Low Reynolds 
Number Airfoils," AIAA Journal, vol. 25, no. 10, 1987, pp. 1347-1355.

${ }^{18}$ Jones, B. Melville, "The Measurement of Profile Drag by Pitot Traverse Method," Reports and Memoranda no. 1688, Brit. A.R.C., Jan. 1936.

${ }^{19}$ Silverstein, A. and S. Katzoff, "A Simplified Method for Determining Wing Profile Drag in Flight," J. Aeronautical Sci., vol. 7, 1940, pp. 195-301.

${ }^{20}$ Coleman, Hugh W. and W. Glenn Steele, Jr., Experimentation and Uncertainty Analysis for Engineers, John Wiley \& Sons, New York, 1989.

${ }^{21}$ Marchman, J. F., "Aerodynamic Testing at Low Reynolds Numbers," J. Aircraft, vol. 24, no. 2, Feb. 1987, pp. 107-114.

${ }^{22}$ Arnaiz, Henry H., Flight-Measured Lift and Drag Characteristics of a Large, Flexible, High Supersonic Cruise Airplane, NASA TM X-3532, May 1977.

${ }^{23}$ Montoya, L. C., R. D. Banner, and P. F. Bikle, "Section Drag Coefficients From Pressure Probe Trasverses of a Wing Wake at Low Speeds," AIAA 78-1479, Aug. 1978.

${ }^{24}$ Allen, Jerry M., Pitot-Probe Displacement in a Supersonic Turbulent Boundary Layer, NASA TN D-6759, Apr. 1972.

${ }^{25}$ Batill, Stephen M. and Thomas J. Mueller, "Visualization of Transition in the Flow Over an Airfoil Using the Smoke-Wire Technique," AIAA Journal, vol. 19, no. 3, 1981, pp. 340-345. (Also AIAA 80-0421R.)

${ }^{26}$ Guglielmo, James J. and Michael S. Selig, "Large Spanwise Variations in Profile Drag for Airfoils at Low Reynolds Numbers," AIAA 95-1783, 1995.

${ }^{27}$ Bastedo, W. G., Jr., and T. J. Mueller, "Spanwise Variation of Laminar Separation Bubbles on Wings at Low Reynolds Numbers," J. Aircraft, vol. 23, no. 9, Sept. 1986, pp. 687-694.
${ }^{28}$ Chiles, Harry R., The Design and Use of a Temperature-Compensated Hot-Film Anemometer System for Boundary-Layer Flow Transition Detection on Supersonic Aircraft, NASA TM-100421, May 1988.

${ }^{29}$ Mangalam, Siva M., John P. Stack, and W. G. Sewall, "Simultaneous Detection of Separation and Transition in Surface Shear Layers," in Fluid Dynamics of Three-Dimensional Turbulent Shear Flows and Transition, AGARD CP-438, 1988, pp. 12-1 to 12-10.

${ }^{30}$ Rogallo, Vernon L., Effects of Wing Sweep on the Upwash at the Propeller Planes of Multiengine Airplanes, NACA TN-2795, 1952.

${ }^{31}$ Barna, P. S. and Gary R. Crossman, Experimental Studies on the Aerodynamic Performance and Dynamic Response of Flow Direction Sensing Vanes, NASA CR-2683, May 1976.

${ }^{32}$ Friehe, Carl A. and Djamal Khelif, "Fast-Response Aircraft Temperature Sensors," J. Atmospheric and Oceanic Tech., vol. 9, no. 6, Dec. 1992, pp. 784-795.

${ }^{33}$ Liebeck, Robert H., "Low Reynolds Number Airfoil Design for Subsonic Compressible Flow," in Low Reynolds Number Aerodynamics Proceedings, 1989, pp. 314-330.

${ }^{34}$ McGhee, Robert J., Betty S. Walker, and Betty F. Millard, Experimental Results for the Eppler 387 Airfoil at Low Reynolds Numbers in the Langley LowTurbulence Pressure Tunnel, NASA TM-4062, Oct. 1988.

${ }^{35}$ Gaster, M., "The Structure and Behaviour of Laminar Separation Bubbles," in Separated Flows, AGARD CP-4, 1966, pp. 813-854.

${ }^{36}$ Gruber, K., H. Bestek, and H. Fasel, "Interaction Between a Tollmien-Schlichting Wave and a Laminar Separation Bubble," AIAA 87-1256, 1987. 
Public reporting burden for this collection of information is estimated to average 1 hour per response, including the time for reviewing instructions, searching existing data sources, gathering and maintaining the data needed, and completing and reviewing the collection of information. Send comments regarding this burden estimate or any other aspect of this collection of information, Including suggestions for reducing this burden, to Washıngton Headquarters Services, Directorate for Informatıon Operations and Reports, 1215 Jefferson Davis Highway, Suite 1204, Arlington, VA 22202-4302, and to the Office of Management and Budget, Paperwork Reduction Project (0704-0188), Washington, DC 20503.

1. AGENCY USE ONLY (Leave blank)

\section{REPORT DATE}

3. REPORT TYPE AND DATES COVERED

July 1999

Technical Memorandum

\section{TITLE AND SUBTITLE}

Design and Predictions for a High-Altitude (Low-Reynolds-Number)

Aerodynamic Flight Experiment

6. AUTHOR(S)

Donald Greer, Phil Hamory, Keith Krake, and Mark Drela.

\section{PERFORMING ORGANIZATION NAME(S) AND ADDRESS(ES)}

NASA Dryden Flight Research Center

P.O. Box 273

Edwards, California 93523-0273

9. SPONSORING/MONITORING AGENCY NAME(S) AND ADDRESS(ES)

National Aeronautics and Space Administration

Washington, DC 20546-0001
529-1004-0029-00-APE

\section{FUNDING NUMBERS}

8. PERFORMING ORGANIZATION REPORT NUMBER

H-2340

10. SPONSORING/MONITORING AGENCY REPORT NUMBER

NASA/TM-1999-206579

\section{SUPPLEMENTARY NOTES}

Presented at the 17th Applied Aerodynamics Conference and 14th Computational Fluid Dynamics Conference, Norfolk, Virginia, June 28-July 1, 1999, AIAA 99-3183.

12a. DISTRIBUTION/AVAILABILITY STATEMENT 12b. DISTRIBUTION CODE

Unclassified-Unlimited

Subject Category 02

13. ABSTRACT (Maximum 200 words)

A sailplane being developed at NASA Dryden Flight Research Center will support a high-altitude flight experiment. The experiment will measure the performance parameters of an airfoil at high altitudes $(70,000$ to $100,000 \mathrm{ft}$ ), low Reynolds numbers $(200,000$ to 700,000$)$, and high subsonic Mach numbers $(0.5$ and 0.65$)$. The airfoil section lift and drag are determined from pitot and static pressure measurements. The locations of the separation bubble, Tollmien-Schlichting boundary layer instability frequencies, and vortex shedding are measured from a hot-film strip. The details of the planned flight experiment are presented. Several predictions of the airfoil performance are also presented. Mark Drela from the Massachusetts Institute of Technology designed the APEX-16 airfoil, using the MSES code. Two-dimensional Navier-Stokes analyses were performed by Mahidhar Tatineni and Xiaolin Zhong from the University of California, Los Angeles, and by the authors at NASA Dryden.

\section{SUBJECT TERMS}

Airfoils, High altitude, Low Reynolds numbers, Sailplane, Transition

\section{NUMBER OF PAGES}

23

16. PRICE CODE

A03

17. SECURITY CLASSIFICATION

OF REPORT

Unclassified

18. SECURITY CLASSIFICATION

OF THIS PAGE

Unclassified
19. SECURITY CLASSIFICATION OF ABSTRACT

Unclassified
20. LIMITATION OF ABSTRACT

Unlimited 